\title{
Effects of Combined Exercise Program on Body Composition, Lipid and Cortisol Levels in Blood Among Middle School Students with Intellectual Disability
}

\author{
https://doi.org/10.3991/ijoe.v16i13.18723 \\ Kun-Woo Park \\ Yong-In University, Yongin, South Korea \\ Seung-Yong Kim ${ }^{(凶)}$ \\ Kyonggi University, Suwon, South Korea \\ dragonkimekyonggi.ac.kr
}

\begin{abstract}
The purpose of this study was to identify physiological responses through combined exercise for intellectually disabled people who view obesity as one of their physical characteristics. To achieve the purpose of this study, an eight-week compound exercise was conducted on 28 intellectually disabled middle school students residing in $\mathrm{K}$ city and the average and standard deviation for groups (normal BMI groups, obese BMI groups) were calculated. In addition, data processing was performed using two-way repeated measured ANOVA using SPSS 18.0, and post-verification was performed if there were significant differences. The results are as follows: First, there was no change in weight for middle school students with intellectual disabilities through eight weeks of combined exercise. However, the lean body mass increased in the standard population, body fat mass and BMI decreased in the standard population, and the bone density factor increased in both the standard population and the obese population. Second, neutral fat decreased in the standard group, and the low-density cholesterol factor decreased in the obesity group. Third, cortisol factors have been shown to decrease in standard groups. In conclusion, the eight-week compound exercise has been shown to have an effect of improvement in the physical composition and blood lipid variables of middle school students with intellectual disabilities.
\end{abstract}

Keywords - Combined exercise program, body composition, lipid, cortisol, intellectual disability

\section{Introduction}

For people with disabilities, participating in sports activities on a regular basis improves health and motor functions, leading to social engagement rather than isolation [1]. According to the statistical data available from the Ministry of Health and Welfare of the Republic of Korea, the number of registered people with intellectual disability is about 200,000, which accounts for $8.0 \%$ of the disabled population [2]. Depending on the individual difference, major developmental milestones that are expected to appear 
as a child grows tend to develop less successfully, including attention deficit, emotional maladjustment, hyperactivity, impaired motor function, lethargy, and sensory deficiency, all of which are characteristics of mental, physical, and social domains [3].

Adolescence is a developmental period during which the child attends middle school, and it is thought to be an important developmental stage that brings about significant physical and mental changes. However, in case of students with intellectual disability, there is an increase of passive behavior consisted of following instructions and orders rather than active behavior, which puts limitation on self-directed activities, resulting in negative consequences in terms of the idea of individuality and forming social relationships [4].

Specifically, because intellectually disabled students lack physical activity, there is an increased risk of obesity because the sensor that balances energy status by regulating the amount of stored triglycerides in fat cells loses control $[5,6]$. Obesity also is a major cause of osteoporosis due to decreased bone density [7]. Thus, because intellectually disabled students show high prevalence of obesity [5,8] and desire for food consumption [9] in addition to decreased motor function as they age, there is an urgent interventional need for effective weight management [10]. To prevent the risk of obesity and metabolic syndrome, combined exercise consisted of aerobic and resistance exercise is effective in inducing growth hormone for development and weight control [11-13]. It also suppresses appetite, which is a positive benefit to treat obesity [14].

In relevance to the discussion above, there has been research effort for students with intellectual disabilities on combined exercise $[15,16]$, association between exercise period and physical activity and fitness [17,18], and relationship between the intensity of physical exercise and body composition [19]. However, there is a lack of research on the association between combined exercise and changes in body composition, blood lipid and cortisol levels. Therefore, the present study entails an important meaning, because it attempts to delineate physiologic response to combined exercise among the people with intellectual disability.

\section{$2 \quad$ Research Method}

\subsection{Subjects}

The study subjects were middle school students drawn from facilities and special schools located in "K" city, Republic of Korea, who were diagnosed with intellectual disability from healthcare institutions. The subjects were selected based on the fact that they had ability to communicate with the research personnel, had no visual or auditory defects, were not participating in any drug abuse treatment program at the start of the study, and did not have problem in performing daily life activities. The selection was made among the students who were considered to have low level of physical activity based on the International Physical Activity Questionnaire (IPAQ).

The investigator explained the study purpose, duration, method, and what the research was intended to conclude based on the results to the study participants and their parents, and acquired voluntary consent from them. Specific circumstances of each 
participant were fully discussed through telephone and writing to minimize any possibility of concern expressed by the parents. Table 1 summarizes physical characteristics of the study participants.

Table 1. Subject's physical characteristics $(\mathrm{M} \pm \mathrm{SD})$

\begin{tabular}{|c|c|c|c|c|l|}
\hline Variable & Age (years) & Height (cm) & Weight (kg) & $\begin{array}{c}\text { Body fat } \\
\text { percentage (\%) }\end{array}$ & Disability level \\
\hline NBG & 15.93 & 163.68 & 51.60 & 16.22 & Intellectual Disability \\
(N=16) & \pm 0.25 & \pm 5.33 & \pm 8.70 & \pm 6.34 & Level 3 \\
\hline OBG & 15.67 & 163.19 & 70.45 & 37.35 & Intellectual Disability \\
(N=12) & \pm 0.49 & \pm 8.59 & \pm 14.87 & \pm 7.84 & Level 3 \\
\hline NBG: normal body mass index group, OBG: obesity body mass index group \\
\hline
\end{tabular}

\subsection{Study design}

Our study was conducted as a repeated measurement experiment by dividing the participants into normal and obese groups to understand the changes in body composition, blood lipid and cortisol levels, the latter of which is known to be related to obesity, in association with BMI among the middle school students with intellectual disability. Group assignment was carried out according to the Asia-Pacific Obesity Criteria of the World Health Organization proposed by the Korean Society for the Study of Obesity [20]. Among the 28 students with intellectual disability, 16 were assigned to normal BMI group ( $\leqq 25 \mathrm{~kg} / \mathrm{m}^{2}$ ), while 12 were assigned to the obese group ( $\geqq 25 \mathrm{~kg} / \mathrm{m}^{2}$ ).

The subjects were to participate 3 sessions per week for 8 weeks, 60 minutes per session, for a total of 24 sessions. They did not participate in any physical activity other than suggested by the study. To encourage participation in the study, one research assistant was assigned per 2 subjects for the training. We measured body composition, blood lipid and cortisol levels before and after the combined exercise program (aerobic and anaerobic) to quantify the difference.

The combined exercise program was modified for the purpose of our study based on the training evidence from Song [12] and Hwang [13]. Because there is individual difference in physical ability, we selected optimal exercise intensity consisted of anaerobic exercise by applying exercise intensity in small increments and aerobic exercise which utilizes cardiopulmonary endurance for the students with intellectual disability. We modified the intensity depending on each participant to strengthen core muscles and motor functions, which frequently deteriorate in the absence of physical activity.

\subsection{Combined exercise program}

The detailed program was consisted of warm-up exercise, main exercise, cool-off exercise. One session was made of 10 minutes of warm-up, 40 minutes of main exercise, and 10 minutes of cool-off, for a total of 60 minutes. The exercise occurred 3 times per week for 8 weeks. The intensity of exercise was checked by using the Borg index, a subjective measure of exercise intensity, and hear rate. In consideration of the subject population, exercise intensity was managed at 11 to 14 of RPE. In our study, the main 
exercise session of the combined exercise program was planned to target large muscles and cardiopulmonary endurance training. The first part of the large muscle training involved sit-ups, where the participant raised knees perpendicular to the ground while lying down on the floor. The assistant held both feet, while the participant, with both hands behind the head, raised the trunk until both elbows reached the knees. It mainly recruited abdominal muscles by repeatedly flexing and extending. Secondly, jumping in place involved jumping repeatedly as high as the participant could while standing still, with maximal effort to have the knees touch the chest. Lastly, push-ups with both knees on the ground, which was considered lower-intensity than regular push-ups, were carried out in consideration of the participants in the study having disability.

Cardiopulmonary endurance exercise included side walking, agile walking, jumping rope, and long-distance running. Side walking was adopted from the side step test by having the subject shifting left and right at a distance of $120 \mathrm{~cm}$ relative to the center. Agile walking was adopted from the step ladder exercise. A ladder-shaped step ladder was prepared, and the subject was instructed to move on foot at a time so that if both feet were in one spot, he or she could move to the next. To increase agility, subjects were asked to move as fast as they could. Jumping rope and long-distance running were performed according to the subject's level of fitness. Subjects who were unfamiliar with jumping rope were allowed to take two steps to jump the rope. Throughout the exercise, heart rate was checked repeatedly to make sure the intensity remained the same.

For the exercise, warm-up and cool-off were performed at RPE $9-11$, which involved exercise with bare hands such as stretching, walking, and running. The details of the types, time and frequency of the combined exercise program is summarized in Table 2.

Table 2. Combined exercise program

\begin{tabular}{|c|l|l|l|l|}
\hline Phase & \multicolumn{1}{|c|}{ Type } & \multicolumn{1}{|c|}{ Exercise } & Time & Frequency \\
\hline Warm-up & Stretching & $\begin{array}{l}\text { Stretching } \\
\text { Walking, Running } \\
\text { Hands Free }\end{array}$ & 10 minutes \\
\hline Main & $\begin{array}{l}\text { Major } \\
\text { Muscle }\end{array}$ & $\begin{array}{l}\text { Sit-ups } \\
\text { Jumping in Place } \\
\text { Push-up with Knees on Ground }\end{array}$ & \multirow{2}{*}{$\begin{array}{l}3 \text { times minutes } \\
\text { Mardiopul- }\end{array}$} & $\begin{array}{l}\text { Side Walking } \\
\text { Agile Walking } \\
\text { Jumping Rope } \\
\text { Distance Running }\end{array}$ \\
\cline { 2 - 4 } Cool-off & Stretching & $\begin{array}{l}\text { Stretching } \\
\text { Hands Free }\end{array}$ & 10 minutes & \\
\hline
\end{tabular}

In our experimental design, although both groups performed the same combined exercise program, because the subject population had a low level of physical activity and a diverse range of motor abilities, the same level of energy expenditure was applied across the subject groups. To achieve this, during the pilot phase of the study, subjects used a wireless portable gas analyzer to measure the energy consumption (kcal) during 
the combined exercise methods. Energy consumption of the two groups is shown in Table 3. An independent t-test was performed to analyze the difference in energy consumption between the two groups, but there was no significant difference found.

Table 3. Results of energy consumption (kcal) between groups

\begin{tabular}{|c|c|c|c|}
\hline Variable & NBG $(\mathbf{M} \pm$ SD) & OBG $(\mathbf{M} \pm$ SD $)$ & t \\
\hline Energy expenditure $(\mathrm{kcal})$ & $121.54 \pm 4.24$ & $119.24 \pm 5.26$ & .774 \\
\hline
\end{tabular}

\subsection{Measurement tool, parameter and method}

Measurement tools used in the study are listed in Table 4.

Table 4. Measurement tools

\begin{tabular}{|l|l|l|l|}
\hline \multicolumn{1}{|c|}{ Purpose } & \multicolumn{1}{|c|}{ Variables } & \multicolumn{1}{c|}{ Tool } & \multicolumn{1}{c|}{$\begin{array}{c}\text { Model } \\
\text { (Country of Manufacture) }\end{array}$} \\
\hline Body Composition & Weight, Body Fat \% & In body 520 & Biospace (Korea) \\
\hline $\begin{array}{l}\text { Cardiopulmonary } \\
\text { Test }\end{array}$ & kcal, Oxygen Consumption & K4b2 & Cosmed (Italia) \\
\hline Heart Rate & Heart Rate & Polar, RS800 & Polar (Finland) \\
\hline DEXA & $\begin{array}{l}\text { Body Fat \%, Body Fat Mass, } \\
\text { Lean Body Mass, Bone Density }\end{array}$ & Lunar prodigy & GE medical systems (USA) \\
\hline $\begin{array}{l}\text { Analysis of Blood } \\
\text { Levels of Interest }\end{array}$ & $\begin{array}{l}\text { TC, TG, HDL-C, LDL-C, Glu- } \\
\text { cose, Cortisol }\end{array}$ & & \\
\hline
\end{tabular}

In the study, energy consumption was measured by the Graded Exercise Test. The maximum graded exercise test was conducted at room temperature below $22^{\circ} \mathrm{C}$ and humidity below $60 \%$. After wearing the gas analyzer and heart rate monitor, warm-up and cool-down walking exercises were performed at $1.5 \mathrm{mph}$ and $0 \%$ angle for 3 minutes. The gas analyzer was calibrated before the test.

The subjects were encouraged to do the graded exercise to their maximal capacity by allowing them to rest until their heart rates returned to normal after warm-up. The protocol used for the maximal graded exercise test adopted a speed at 3.3 miles per hour. Slope inclination adopted Balke-Ware protocol, where the slope began at $2 \%$ with additional $1 \%$ every minute. For the graded maximal exercise test, to determine the point of test termination the respiratory exchange rate was set at 1.15 or higher, expected maximum heart rate $(220$ - age) or higher, exercise awareness at 19 or higher, when the oxygen intake level remains the same even when the exercise intensity increased, or for any reason that makes it difficult for the subject to continue the exercise [21].

Heart rate measurement involved having the research subjects to remove the top clothing, attaching a polar sensor belt at the two-thirds the chest height, and wearing a watch designed to measure the heart rate. During measurement, heart rate data was saved automatically every 15 seconds. After the measurement, stored data in the watch was transferred to the PC. 
Body composition test was carried out before and after ( 8 week) the combined exercise program completion, both done in the same method. To be consistent with daily variation, height and weight were measured before $10 \mathrm{AM}$. Body composition was measured with a Dual-Energy X-ray Absorptiometry Technique (DEXA) to acquire bodyweight $(\mathrm{kg})$, body fat percentage $(\% \mathrm{BF})$, body fat mass $(\mathrm{BFM})$, and fat free mass (FFM). To achieve accuracy in measurements, subjects were instructed to refrain from any strenuous exercise 12 hours before the test. They were told not to consume any food 6 hours before the test. Measurements were made with subjects wearing light clothes, lying down with hands and foot touching each other.

In respect to analyzing blood lipids and cortisol, $10 \mathrm{~mL}$ of venous blood was collected from a major vein in forearms with disposable syringes. Collected venous blood samples were centrifuged at 3,000 rpm for minutes, followed by freezing at $-70^{\circ} \mathrm{C}$. They were then analyzed by commissioning the S Medical Foundation.

\subsection{Processing the data}

To analyze the data of our study, a statistical software SPSS version 18.0 program was used to calculate the mean and standard deviation of the variable of interest. To test the difference between the groups (normal BMI group, obese BMI group) based on the 8 -week combined exercise program and the period (prior, at 8 weeks) in relation to body composition, blood lipid indicators and cortisol, we utilized a two-way repeated measured ANOVA. If there is any significant difference, we performed a post-hoc test. We set the significance level at 0.05 in all the statistical tests performed.

\section{Results}

\subsection{Body composition (Bodyweight, Lean body mass, Body fat mass, BMI) changes}

After conducting the 8-week combined exercise program on the middle school student with intellectual disability, changes to their weight, lean body mass, body fat mass, and BMI are shown in Table 5. 
Table 5. Body composition (Weight, Lean body mass, Body fat mass, BMI), mean and standard deviations

\begin{tabular}{|l|l|c|c|c|}
\hline \multicolumn{1}{|c|}{ Variable } & \multicolumn{1}{|c|}{ Group } & Pre $(\mathbf{M} \pm$ SD) & Post $(\mathbf{M} \pm$ SD) & t \\
\hline \multirow{2}{*}{ Weight $(\mathrm{kg})$} & NBG & $51.60 \pm 8.70$ & $51.30 \pm 8.63$ & .833 \\
\cline { 2 - 5 } & OBG & $70.74 \pm 15.56$ & $70.06 \pm 16.05$ & 1.162 \\
\hline \multirow{2}{*}{ Lean body mass $(\mathrm{kg})$} & NBG & $39.51 \pm 5.75$ & $41.68 \pm 6.38$ & $-4.609^{* * *}$ \\
\cline { 2 - 5 } & OBG & $40.18 \pm 6.90$ & $41.67 \pm 8.69$ & $-2.888^{* *}$ \\
\hline \multirow{2}{*}{ Body fat mass $(\mathrm{kg})$} & NBG & $7.99 \pm 3.93$ & $7.40 \pm 3.53$ & $3.552^{* *}$ \\
\hline \multirow{2}{*}{\begin{tabular}{l} 
BMI $\left(\mathrm{kg} / \mathrm{m}^{2}\right)$ \\
\cline { 2 - 5 }
\end{tabular}} & OBG & $25.25 \pm 9.14$ & $25.02 \pm 9.62$ & 1.367 \\
\hline $\begin{array}{l}\text { NBG: normal body mass index group, OBG: obesity body mass index group } \\
{ }_{*}^{* * *} \mathrm{p}<.001,{ }^{* *} \mathrm{p}<.01\end{array}$ & NBG & $16.22 \pm 6.34$ & $14.82 \pm 5.98$ & $4.879^{* * *}$ \\
\cline { 2 - 5 } & OBG & $36.74 \pm 8.78$ & 1.937 \\
\hline
\end{tabular}

In addition, results of the 2-way repeated measured ANOVA on the changes to the weight, lean body mass, body fat mass, and BMI in the 8-week combined exercise program on the middle school student with intellectual disability, are shown in Table 6.

Table 6. Body composition between groups (Weight, Lean body mass, Body fat mass, BMI) two-way repeated ANOVA

\begin{tabular}{|l|l|c|c|c|c|}
\hline & \multicolumn{1}{|c|}{ Variable } & SS & df & MS & F-value \\
\hline \multirow{4}{*}{ Weight $(\mathrm{kg})$} & Group & 2280.013 & 1 & 2280.013 & .001 \\
\cline { 2 - 6 } & Period & 3.059 & 1 & 3.059 & .146 \\
\cline { 2 - 6 } & Group x Period & .463 & 1 & .463 & .565 \\
\hline \multirow{5}{*}{ Lean body mass $(\mathrm{kg})$} & Group & 523886.027 & 1 & 523886.027 & .011 \\
\cline { 2 - 7 } & Period & 44457842.45 & 1 & 44457842.45 & $14.695^{* * *}$ \\
\cline { 2 - 6 } & Group x Period & 1082983.220 & 1 & 1082983.220 & .358 \\
\hline \multirow{3}{*}{ Body fat mass $(\mathrm{kg})$} & Group & $1.949 \mathrm{E} 9$ & 1 & $1.949 \mathrm{E} 9$ & $41.997^{* * *}$ \\
\cline { 2 - 6 } & Period & 3161126.657 & 1 & 3161126.657 & $9.704^{* * *}$ \\
\cline { 2 - 6 } & Group x Period & 102524.042 & 1 & 102524.042 & .315 \\
\hline \multirow{3}{*}{ BMI $\left(\mathrm{kg} / \mathrm{m}^{2}\right)$} & Group & 2954.983 & 1 & 2954.983 & $56.817^{* * * *}$ \\
\cline { 2 - 6 } & Period & 14.219 & 1 & 14.219 & $21.067^{* * *}$ \\
\cline { 2 - 6 } & Group x Period & 1.469 & 1 & 1.469 & 2.177 \\
\hline$* * * \mathrm{p}<.001$ & & & & \\
\hline
\end{tabular}

The results of body composition show that first, as a result of analyzing weight change, group $(\mathrm{F}=0.001)$ and period $(\mathrm{F}=0.146)$ as the main effects, and the interaction between group and period $(\mathrm{F}=0.565)$ did not show statistical difference. Second, after analyzing lean body fat change prior and after the exercise program, period $(\mathrm{F}=14.695$, $\mathrm{p}=0.000)$ showed a statistically significant difference, but group $(\mathrm{F}=0.011)$ and the interaction between group and period did not show any effect $(\mathrm{F}=0.358)$. Third, after analyzing the change in body fat mass, group $(\mathrm{F}=41.997, \mathrm{p}=0.000)$ and period $(\mathrm{F}=9.704$, $\mathrm{p}=0.000$ ) as the main effects showed statistically significant differences, but such significance was not seen in the interaction between group and period $(\mathrm{F}=0.315)$. Fourth, 
when changes in BMI were analyzed, group $(\mathrm{F}=56.817, \mathrm{p}=0.001)$ and period $(\mathrm{F}=21.067, \mathrm{p}=0.001)$ as main effects did exhibit statistically significant differences, but the interactive effect $(\mathrm{F}=2.177)$ between group and period was not observed.

\subsection{Changes in blood lipids (Cholesterol, Triglyceride, HDL-C, LDL-C, Glucose)}

After having conducted 8 weeks of combined exercise program on intellectually disabled middle school students, the resulting changes in cholesterol, triglyceride, HDLC, LDL-D, and glucose are shown in Table 7.

Table 7. Blood lipids (Cholesterol, Triglycerides, HDL-C, LDL-C, Glucose), mean and standard deviation

\begin{tabular}{|l|l|c|c|c|}
\hline \multicolumn{1}{|c|}{ Variable } & Group & Pre $(\mathbf{M} \pm$ SD) & Post $(\mathbf{M} \pm$ SD) & t \\
\hline \multirow{2}{*}{ Cholesterol $(\mathrm{mg} / \mathrm{dl})$} & NBG & $133.27 \pm 20.15$ & $134.07 \pm 21.13$ & -.300 \\
\cline { 2 - 5 } & OBG & $162.00 \pm 23.39$ & $164.73 \pm 21.25$ & -.586 \\
\hline \multirow{2}{*}{ Triglyceride $(\mathrm{mg} / \mathrm{dl})$} & NBG & $63.00 \pm 35.28$ & $60.40 \pm 17.60$ & .273 \\
\cline { 2 - 5 } & OBG & $109.36 \pm 38.29$ & $107.36 \pm 47.29$ & .166 \\
\hline \multirow{2}{*}{ HDL/C $(\mathrm{mg} / \mathrm{dl})$} & NBG & $59.73 \pm 13.81$ & $61.33 \pm 16.62$ & -.686 \\
\cline { 2 - 5 } & OBG & $49.45 \pm 8.92$ & $52.00 \pm 10.49$ & -1.438 \\
\hline \multirow{2}{*}{ LDL/C $(\mathrm{mg} / \mathrm{dl})$} & NBG & $68.13 \pm 13.21$ & $69.53 \pm 15.78$ & -.566 \\
\cline { 2 - 5 } & OBG & $104.09 \pm 22.30$ & $102.09 \pm 18.37$ & .563 \\
\hline \multirow{2}{*}{ Glucose $(\mathrm{mg} / \mathrm{dl})$} & NBG & $81.07 \pm 11.84$ & $85.73 \pm 6.90$ & -1.350 \\
\cline { 2 - 5 } & OBG & $85.45 \pm 8.44$ & $84.64 \pm 11.93$ & .203 \\
\hline NBG: normal body mass index group, OBG: obesity body mass index group \\
\hline
\end{tabular}

In addition, after having conducted 8 weeks of combined exercise program on intellectually disabled middle school students, the results of 2-way repeated measured ANOVA in cholesterol, triglyceride, HDL-C, LDL-D, and glucose are shown in Table 8 . 
Table 8. Blood lipids between groups (Cholesterol, Triglycerides, HDL-C, LDL-C, Glu-cose), two-way repeated ANOVA

\begin{tabular}{|c|c|c|c|c|c|}
\hline & Variable & SS & df & MS & F-value \\
\hline \multirow{3}{*}{ Cholesterol (mg/dl) } & Group & 5596.737 & 1 & 5596.737 & $13.437^{\text {*** }}$ \\
\hline & Period & 39.478 & 1 & 39.478 & .491 \\
\hline & Group x Period & 11.786 & 1 & 11.786 & .706 \\
\hline \multirow{3}{*}{ Triglyceride (mg/dl) } & Group & 13818.718 & 1 & 13818.718 & $16.084^{* * *}$ \\
\hline & Period & 67.142 & 1 & 67.142 & .092 \\
\hline & Group x Period & 1.142 & 1 & 1.142 & .002 \\
\hline \multirow{3}{*}{ HDL/C (mg/dl) } & Group & 610.239 & 1 & 610.239 & 3.807 \\
\hline & Period & 54.529 & 1 & 54.529 & 1.759 \\
\hline & Group x Period & 2.836 & 1 & 2.836 & .091 \\
\hline \multirow{3}{*}{$\mathrm{LDL} / \mathrm{C}(\mathrm{mg} / \mathrm{dl})$} & Group & 7447.729 & 1 & 7447.729 & $27.602^{* * *}$ \\
\hline & Period & 1.142 & 1 & 1.142 & .021 \\
\hline & Group x Period & 36.681 & 1 & 36.681 & .659 \\
\hline \multirow{3}{*}{ Glucose (mg/dl) } & Group & 17.182 & 1 & 17.182 & .315 \\
\hline & Period & 46.996 & 1 & 46.996 & .525 \\
\hline & Group x Period & 95.457 & 1 & 95.457 & 1.066 \\
\hline
\end{tabular}

With respect to the lipid levels, first, when changes in cholesterol were analyzed, there was a statistically significant difference in group as the main effect $(\mathrm{F}=13.437$, $\mathrm{p}=0.001)$. However, there was no effect in the period $(\mathrm{F}=0.491)$ nor in the interaction between group and period $(\mathrm{F}=0.706)$. Second, when changes in triglyceride were analyzed, there was a statistically significant difference in group as the main effect $(\mathrm{F}=16.084, \mathrm{p}=0.001)$. But there was no effect in the period $(\mathrm{F}=0.092)$ and the interaction between group and period $(\mathrm{F}=0.002)$. Third, when changes in $\mathrm{HDL} / \mathrm{C}$ were analyzed, there was no significant difference in group $(\mathrm{F}=3.807)$ or period $(\mathrm{F}=1.759)$ as the main effect. No effect in the interaction between group and period was seen $(\mathrm{F}=0.091)$. Fourth, when changes in LDL/C were analyzed, there was a statistically significant difference in group as the main effect $(\mathrm{F}=27.602, \mathrm{p}=0.000)$, but no effect was seen in the period $(\mathrm{F}=0.021)$ or the interaction between group and period $(\mathrm{F}=0.659)$. Fifth, when changes in glucose were analyzed, no significant difference was observed in group $(\mathrm{F}=0.315)$ or period $(\mathrm{F}=0.525)$ as the main effects, nor there was any effect $(\mathrm{F}=1.066)$ in the interaction between the group and period.

\subsection{Cortisol}

Changes in cortisol levels after conducting 8 weeks of combined exercise program on intellectually disabled middle school students is shown in Table 9. 
Paper-Effects of Combined Exercise Program on Body Composition, Lipid and Cortisol Levels...

Table 9. Cortisol level, mean and standard deviation

\begin{tabular}{|l|l|c|c|c|}
\hline \multicolumn{1}{|c|}{ Variable } & \multicolumn{1}{|c|}{ Group } & Pre $($ Mean \pm SD) & Post $($ Mean \pm SD) & t \\
\hline \multirow{2}{*}{ Cortisol $(\mathrm{mg} / \mathrm{dl})$} & NBG & $4.51 \pm 1.32$ & $4.38 \pm 1.34$ & .235 \\
\cline { 2 - 5 } & OBG & $5.98 \pm 3.10$ & $8.32 \pm 4.33$ & $-3.259^{* *}$ \\
\hline $\begin{array}{l}\text { NBG: normal body mass index group, OBG: obesity body mass index group } \\
{ }^{* *} \mathrm{p}<.01\end{array}$ \\
\hline
\end{tabular}

The results of 2-way repeated measured ANOVA in cortisol level change among the students after participating in 8 weeks of combined exercise program are presented in Table 10.

Table 10. Cortisol level between groups, two-way repeated ANOVA

\begin{tabular}{|l|l|c|c|c|c|}
\hline & \multicolumn{1}{|c|}{ Variable } & SS & df & MS & F-value \\
\hline \multirow{3}{*}{ Cortisol (mg/dl) } & Group & 46.370 & 1 & 46.370 & $8.181^{* *}$ \\
\cline { 2 - 6 } & Period & 15.486 & 1 & 15.486 & $6.006^{*}$ \\
\cline { 2 - 6 } & Group x Period & 19.429 & 1 & 19.429 & $7.536^{*}$ \\
\hline${ }^{* * *} \mathrm{p}<.01,{ }^{*} \mathrm{p}<.05$
\end{tabular}

When scrutinized, after having analyzed cortisol level changes, there were significant differences in the group $(\mathrm{F}=8.181, \mathrm{p}=0.009)$, period $(\mathrm{F}=6.006, \mathrm{p}=0.022)$, and the interaction between the group and period $(\mathrm{F}=7.536, \mathrm{p}=0.011)$.

\section{Discussion}

We intend to discuss the results of the study as follows. First, it is known that weight and body mass index are highly associated with energy usage and hormonal variations. Also, children with intellectual disabilities who show significantly low levels of physical activity compared to their counterparts remain inactive in their adulthood [22]. In the current study, after applying combined exercise program for middle school students with intellectual disability for 8 weeks, as the results showed, aerobic and resistance training had a decreasing effect on the body mass and body fat [23]. Thus, it is thought that combined exercise program may improve obesity as well as decrease the prevalence of cardiovascular and other chronic diseases in the long run. Previous studies have postulated that high-intensity interval training on adolescents for the same 8-week period did not result in beneficial change in body composition [24]. It indicates that various factors in physical training, such as exercise type, intensity, time and frequency come into play in promoting positive weight change.

Both NBG and OBG groups showed significant increase in fat free mass in the study. Because the fat free mass of the middle school students with intellectual disability improved significantly after applying the 8 -week exercise program, it is thought that to observe meaningful efficacy of the exercise program, at least 8 weeks are required $[25,26]$. For both NBG and OBG groups the body fat decreased after the exercise, which was statistically significant in the NBG group. In previous studies, Kim and Jung [27] 
reported that after applying combined exercise composed of aerobic and resistance training for 16 weeks on students with disability who had body fat percentage of $25 \%$ or more, body fat mass and percentage decreased significantly. When the combined training was carried out on children with intellectual disability for 16 weeks, there was a significant decrease in body fat percentage [28]. Both of these studies, for the most part, agree with the results of the present study. Changes in body fat percentage are the primary factor for increased regular physical activity. Since the study participants are middle school students at puberty, it is suggested that many of them had increased their muscle mass, along with decreases in the body fat.

As a result of the analysis, both NBG and OBG groups had their body mass index decreased. The number was statistically significant for the NBG group, indicating that the exercise program was more efficacious in terms of changing the body mass index. Oviedo et al. [29] reported that when aerobic exercise using elastic bands at 50 to $80 \%$ of intensity with 10 to 15 repetition on disabled subjects who were 20 to 60 years of age for 14 weeks, there was a statistically significant decrease in the body mass index. When the MGL program was conducted for 3 forty-minute sessions per week for 10 weeks on high school students with intellectual disability, there was a statistically significant decrease in the body mass index [30].

Our study results are consistent with other studies, which reported that obese women with intellectual disability who performed combined exercise at 50 to $70 \%$ HRR intensity, 3 times per week for 12 weeks, showed decreases in the body fat mass, body fat percentage, and body mass index [15]. A similar study reported that when aerobic exercise was conducted on adolescents with intellectual disability, their body mass decreased, which further supports the results of our study [28]. People with intellectual disability have, in addition to low level of intelligence, lack physical activity and healthy diet, possibly causing cardiovascular disease during their adult years [31]. Aerobic exercise is helpful in decreasing the risk of cardiovascular or metabolic diseases by improving the blood lipid levels [32].

Based on the results discussed above, combined exercise program is considered to be a part of neurological process for middle school students with intellectual disabilities, where the body becomes organized to be utilized more efficiently in response to external stimuli. It is reported that the exercise changes sensory function and makes positive impact on the independent lives of people who are intellectually disabled [33]. It is very likely that limited mobility and lack of physical activity pervasive among middle school students with intellectual disability result in obesity, which would continue into adulthood. Therefore, it is of utmost importance to improve blood lipid levels in them, to improve their quality of life and encourage social involvement.

Second, while there was a significant difference between the NBG and OBG groups in terms of changes in the total cholesterol and triglyceride levels before and after the 8 -week combined exercise program, there was no significant change within the groups. When the combined exercise was carried out by intensity on intellectually disabled children, total cholesterol decreased significantly in the high-intensity group [25]. When the combined exercise program occurred 3 times per week for 12 weeks on the people who were intellectually disabled, TC, TG and LDL-C levels showed significant decreases [15]. 
The conflicting results from these studies showed that in terms of decreases in lipid levels, exercise intensity is not associated with the total volume of exercise. The important variable in improving lipid metabolism including HDL-C is exercise volume, not intensity [34]. Environmental factors, such as lifestyle and eating behavior, also can influence lipid levels. In another study, when 8-week high-intensity interval training was performed by adult males, HDL-C level was increased significantly, but no significant change in total cholesterol was seen [35]. These results showed that while the benefits of exercise were minimal in subjects who maintained appropriate level of total cholesterol, it is beneficial for those who are overweight or obese in need of improving lipid levels. Thus, it is necessary to devise a research design that considers combinatory effects of exercise intensity, period, and volume.

In the analysis of HDL-C, there was no statistically significant difference between the groups, but both the NBG and OBG groups showed increase, showing a positive effect on the HDL-C level. When aerobic exercise and weight training were applied to the people with intellectual disability for 12 weeks, HDL-C was decreased, LDL-C was increased, and total cholesterol was decreased [26]. There was another study on intellectually disabled children, comparing a group that participated in physical activity 2 times per week for 12 to 18 months versus a group that did not participate, total cholesterol and LDL-C levels decreased significantly, which was partially aligned with the results of our study [36]. Although insignificant in the results of our study, there was an overall beneficial effect. It is shown that regular exercise could promote bodyweight control, activate lipoproteins to break down lipid in bloodstream and lipids on tissue surface, decrease triglyceride and LDL-C, and increase HDL-C, all of which could have preventive effects on cardiovascular disease [37].

After analyzing the changes in LDL-C and glucose levels, they decreased in the OBG group, although insignificantly, indicating that the combined exercise program was more effective than the NBG group. In a previous study, when gym ball program was conducted for 8 weeks on intellectually disabled children who had obesity of body fat percentage at $25 \%$ or more, there was a positive change in the blood lipid levels due to increased physical activity [38]. Though different in subject characteristics, the 8-week combined exercise interval program was more effective in adult males who were overweight than those with normal bodyweight [35]. Taken together, 8 weeks of combined exercise program is thought to lead to a positive effect on blood lipid levels in intellectually disable middle school students.

Third, cortical is a stress hormone secreted by the cells of adrenal cortex, which is greatly influenced by exercise intensity, type, and duration. It promotes sugar production, fat utilization via mobilization of fatty acids in tissues, suppression of the use of glucose, thereby increasing blood glucose levels. It has been reported that glucocorticoids including cortisol are required in response to stressful situations such as strenuous exercise [37].

In respect to cortisol, there was a significant decrease of cortisol in the NBG group, which was absent in the OBG group. In a previous study, cortisol level among male middle school students decreased when a soccer program was conducted 3 times per week for a total of 12 weeks [40]. It was reported in another study about ACTH that cortisol concentration was significantly decreased among the obese female middle 
school students who participated in 10 weeks of combined exercise [41]. In contrast, when a study targeted intellectually disabled males in their 20 to 30 s by applying elastic band exercise for 10 weeks, their cortisol level increased, though insignificantly [42].

These results suggest that for the NBG group there was an improvement of cortisol receptor functions due to the combined exercise program. It could be a result of activating hypothalamus-pituitary-adrenal (HPA) axis and increased responsiveness by continuous exercise. It could also be from low cortisol as a result of increased resistance and tolerance to stress [43]. In a study that investigated association between cortisol and exercise intensity, moderate-level intensity exercise did not significantly change the level of cortisol. However, another study found that as exercise intensity and volume increased, cortisol increase accordingly [44]. Taking them all into consideration, increased cortisol because of persistent stress may lead to the breakdown of fat and protein metabolism. It could eventually lead to changes in blood lipid levels and decreased muscle mass. In other previous studies, when a 30-week track exercise program was conducted on intellectually disabled adolescents, cortisol level decreased by $15.27 \%$ after 15 weeks at 55 to $85 \%$ HRmax intensity. However, after 30 weeks, it increased by $27.05 \%$ [45]. Because cortisol level is influenced by exercise intensity, type, and duration [46], the OBG group would have relatively lower physical activity and basal metabolic rate than the NBG group. While the combined exercise therapy was applied at the same exercise volume, the OBG group perceived the program as of higher exercise intensity, which could have impacted the result of the study. Taken together, the results suggest that numerous factors can influence the level of cortisol. It might be necessary to modify the combined exercise by setting the parameters in details to improve the cortisol level in the OBG group.

\section{Conclusion}

Having conducted the combined exercise program on intellectually disabled middle school students for 8 weeks, we came to the following conclusions. Our 8-week combined exercise program brought enormous physical activity, promoted development of major muscles, and could help with healthier quality of life. Because the exercise was done in intervals, in terms of diversity and irregularities the program could promote active participation and interest from the subjects. Combined exercise program is an effective exercise method for intellectually disable middle school students who lack physical activity to improve independent daily lives and quality of life.

\section{Acknowledgement}

This study summarized and reconstructed the contents of a doctoral dissertation by Kun-Woo Park. 


\section{$7 \quad$ References}

[1] Paik, J. K., \& Lee, I. K. (2007). An analysis of the scoring technique types of the judo players with visual impairments and hearing impairments. Korean Journal of Adapted Physical Activity, 15(4), 159-177. https://doi.org/10.17006/kjapa.2007.15.4.159

[2] Ministry of Health and Welfare (2019). Status of disabled registration 2018. Ministry of Health and Welfare in Korea. Retrieved from: http://www.mohw.go.kr/react/policy/policy_bd_vw.jsp?PAR_MENU_ID=06\&MENU_ID=06370501\&CONT_SEQ=349080

[3] Chae, M. (2009). Interaction-centered group music therapy on the improvement of self-expression and social skill in adults with intellectual disabilities. (Unpublished master's thesis). Daegu University, Gyeongsan, Korea.

[4] Cho, A. Y. (2011). A cases study of participation attitude and emotional purification for on the physical activity program Participation of the mentally handicapped children. (Unpublished master's thesis). Hanshin University, Osan, Korea.

[5] Kwon, H. Y., Lee, W. J., \& Ju, S. B. (2009). The effects of dance program on obesity indices and blood leptin, resistin and adiponectin in obese adolescence of mental retardation. Korea Journal of Sports Science, 18(3), 887-896. UCI: G704-001369.2009.18.3.076

[6] Bouassida, A., Chamari, K., Zaouali, M., Feki, Y., Zbidi, A., \& Tabka, Z. (2010). Review on leptin and adiponectin responses and adaptations to acute and chronic exercise. British Journal of Sports Medicine, 44(9), 620-630. https://doi.org/10.1136/bjsm.2008.046151

[7] Srikanth, R., Cassidy, G., Joiner, C., \& Teeluckdharry, S. (2011). Osteoporosis in people with intellectual disabilities: A review and a brief study of risk factors for osteoporosis in a community sample of people with intellectual disabilities. Journal of Intellectual Disability Research, 55(1), 53-62. https://doi.org/10.1111/j.1365-2788.2010.01346.x

[8] Hsu, S. W., Yen, C. F., Hung, W. J., Lin, L. P., Wu, C. L., \& Lin, J. D. (2012). The risk of metabolic syndrome among institutionalized adults with intellectual disabilities. Research in Developmental Disabilities, 33(2), 615-620. https://doi.org/10.1016/j.ridd.2011.09.005

[9] Francisco, J. O., Gabriel, F. G., Alejandra, C., Miguel, A. R., Lgnacio, R., \& Antonio, J. D. (2013). Anti-inflammatory effect of exercise, via reduced leptin levels, in obese women with Down Syndrome. International Journal of Sport Nutrition and Exercise Metabolism, 23(3), 239-244. https://doi.org/10.1123/ijsnem.23.3.239

[10] Melville, C. A., Cooper, S. A., Morrison, J., Allan, L., Smiley, E., \& Williamson, A. (2008). The prevalence and determinants of obesity in adults with intellectual disabilities. Journal of Applied Research in Intellectual Disabilities, 21(5), 425-437. https://doi.org/10.1111/ j.1468-3148.2007.00412.X

[11] Kim, S. Y., Lee, S. H., \& Yang, J. H. (2013). Effects of combined exercise on dietary intake volume, physique, and body composition in underweight middle school girls. The Korean Journal of Growth and Development, 21(2), 71-76. Retrieved from: http://www.dbpia.co.kr. libproxy.kyonggi.ac.kr:8088/pdf/pdfView.do?nodeId=NODE07024307

[12] Song, C. H. (2013). Effect of resistive exercise program on body composition, blood lipid, and growth-related factors in children with mental retardation. Korean Journal of Adapted Physical Activity, 21(2), 41-56. https://doi.org/10.17006/kjapa.2013.21.2.41

[13] Hwang, E. A., Kim, S. H., Kang, H. S., \& Kim, J. S. (2012). The purpose of this study was to investigate the effects of twelve weeks combined exercise on IL-6, CRP, Resistin related to cardiovascular disease in obese adolescents. Exercise Science, 21(1), 31-40. https://doi. org $/ 10.15857 / \mathrm{ksep} .2012 .21 .1 .31$

[14] Choi, S. Y., \& Byeon, J. M. (2013). The effect of intensity of aerobic exercise program on metabolic syndrome risk factors in obese children. The Korean Journal of Growth and Development, 21(1), 15-23. UCI: G704-001365.2013.21.1.004 
[15] Gim, M. S., \& Song, C. H. (2012). Effects of the combined exercise program on body composition, blood lipid, and leptin in obese women with intellectual disabilities. The Korean Journal of Sport, 10(3), 349-359. UCI: G704-SER000001967.2012.10.4.066

[16] Shin, Y. A., Kim, J. T., Suk, M. H., Lim, K. I., \& Rhyu, H. S. (2010). Effect of basketball program on body composition, metabolic risk factors and physical fitness in overweighted students with intellectual disability. Korean Journal of Adapted Physical Activity, 18(3), 111-126. https://doi.org/10.17006/kjapa.2010.18.3.111

[17] Wu, C. L., Lin, J. D., Hu, J., Yen, C. F., Yen, C. T., Chou, Y. L., \& Wu, P. H. (2010). The effectiveness of healthy physical fitness programs on people with intellectual disabilities living in a disability institution: Six-month short-term effect. Research in Developmental Disabilities, 31(3), 713-717. https://doi.org/10.1016/j.ridd.2010.01.013

[18] George, V. A., Shacter, S. D., \& Johnson, P. M. (2011). BMI and attitudes and beliefs about physical activity and nutrition of parents of adolescents with intellectual disabilities. Journal of Intellectual Disability Research, 55(11), 1054-1063. https://doi.org/10.1111/j.13652788.2011.01437.X

[19] Jang, H. Y., An, J. H., \& Kim, J. H. (2016). Effects of 8-weeks gym-ball exercise program on the body composition and health-related physical fitness and plantar foot pressure on female students with visual impairments. The Korean Journal of Physical Education, 55(5), 729-740. UCI: G704-000541.2016.55.5.010

[20] Korean Society for The Study of Obesity. (2000). The Asia-pacific perspective: redefining obesity and its treatment. 2000, 24-33. Seoul: Korean Society for The Study of Obesity.

[21] American College of Sports Medicine. (2014). ACSM's guidelines for exercise testing and prescription (9th ed.). Lippincott Williams \& Wilins: Baltimore, MD. 162-193. Retrieved from: http://antoinedl.com/fichiers/public/ACSM-guidelines-2014.pdf

[22] Slevin, E., Truesdale-Kennedy, M., McConkey, R., Livingstone, B., \& Fleming, P. (2014). Obesity and overweight in intellectual and non-intellectually disabled children. Journal of Intellectual Disability Research, 58(3), 211-220. https://doi.org/10.1111/j.1365-2788. 2012.01615.x

[23] Donnelly, J. E., Hill, J. O., Jacobsen, D. J., Potteiger, J., Sullivan, D. K., Johnson, S. L., Heelan, K., Hise, M., Fennessey, P. V., Sonko, B., Sharp, T., Jakicic, J. M., Blair, S. N., Tran, Z. V., Mayo, M., Gibson, C., \& Washburn, R. A. (2003). Effects of a 16-month randomized controlled exercise trial on body weight and composition in young, overweight men and women: The midwest exercise trial. Archives of Internal Medicine, 163(11), 1343-1350. https://doi.org/10.1001/archinte.163.11.1343

[24] Calders, P., Elmahgoub, S., De Mettelinge, T. R., Vandenbroeck, C., Dewandele. I., Rombout, L. et al. (2011). Effect of combined exercise training on physical and metabolic fitness in adults with intellectual disability: A controlled trial. Clinical Rehabilitation, 25(12), 1097 1108. https://doi.org/10.1177/0269215511407221

[25] Park, S. H. (2018). Effects of a combined exercise program on the body compositions, physical fitness, blood variables, social skills, and emotional development of children with intellectual disability. (Unpublished Doctoral Dissertation). Kyunghee University, Gyeonggido, Korea.

[26] Kwon, K. S. (2011). The effect of different exercise intensity on blood inflammatory factors and creatine kinase in mentally retarded females. The Korean Journal of Sport, 9(2), 333346. UCI: G704-SER000001967.2011.9.2.001

[27] Kim, S. Y., \& Jung, Y. J. (2008). The effect of complex exercise program on body composition and cardiorespiratory fitness of obese intellectual and developmental disabilities students. Korean Journal of Adapted Physical Activity, 16(3), 167-182. https://doi.org/10.17006/kjapa.2008.16.3.167 
[28] Hwang, J. H. (2011). Effect of 16 weeks combined training on the body composition and physical fitness in the children with mental retardation. (Unpublished master's thesis). Inha University, Incheon, Korea.

[29] Oviedo, G. R., Guerra-Balic, M., Baynard, T., \& Javierre, C. (2014). Effects of aerobic, resistance and balance training in adults with intellectual disabilities. Research in Developmental Disabilities, 35(11), 2624-2634. https://doi.org/10.1016/j.ridd.2014.06.025

[30] Han, S. C. (2012). Body composition and basic physical fitness of students with mental retardation. (Unpublished master's thesis). Daegu University, Gyeongsan, Korea.

[31] Draheim, C. C., Williams, D. P., \& McCubbin, J. A. (2002). Physical activity, dietary intake, and the insulin resistance syndrome in nondiabetic adults with mental retardation. American Journal of Mental Retardation, 107(5), 361-375. https://doi.org/10.1352/0895-8017(2002) $107<0361$ :padiat>2.0.co;2

[32] Pérez, A. B. (2008). Exercise as the cornerstone of cardiovascular prevention. Revista Española de Cardiología (English Edition), 61(5), 514-528. https://doi.org/10.1016/S1885$\underline{5857(08) 60166-8}$

[33] Kim, K. M. (2003). The literature review for assessment of sensory integration. Korean Journal of Occupational Therapy, 11(1), 93-98. Retrieved from: https://www.earticle.net/Arti$\underline{\text { cle/A7928 }}$

[34] Mann, S., Beedie, C., \& Jimenez, A. (2014). Differential effects of aerobic exercise, resistance training and combined exercise modalities on cholesterol and the lipid profile: Review, synthesis and recommendations. Sports Medicine, 44(2), 211-221. https://doi.org/ $10.1007 / \mathrm{s} 40279-013-0110-5$

[35] Musa, D. I., Adeniran, S. A., Dikko, A. U., \& Sayers, S. P. (2009). The effect of a high intensity interval training program on high density lipoprotein cholesterol in young men. The Journal of Strength and Conditioning Research, 23(2), 587-592. https://doi.org/10. 1519/JSC.0b013e318198fd28

[36] Kang, S. Y., \& Park, J. H. (2012). Study on physical activity level and blood lipid in intellectual disabled children. The Korean Journal of Physical Education, 51(1), 487-493. UCI: G704-000541.2012.51.1.017

[37] Sgouraki, E., Tsopanakis, A., \& Tsopanakis, C. (2001). Acute exercise: Response of HDLC, LDL-C lipoproteins and HDL-C subfractions levels in selected sport disciplines. The Journal of Sports Medicine and Physical Fitness, 41(3), 386-391. Retrieved from: https://pubmed.ncbi.nlm.nih.gov/11533571/

[38] Kang, S. A. (2007). Physical activity using gym ball on physical fitness and blood lipid in obese intellectual disabled children. Journal of Korean Physical Education Association for Girls and Women, 21(5), 95-205. UCI: G704-001368.2007.21.5.008

[39] Kim, I. B., Kim, M. K., \& Oh, D. J. (2018). Influence of 12-week combined exercise to health-related fitness, adrenocorticotrophic hormone and cortisol concentration. Korean Journal of Sports Science, 27(3), 973-981. https://doi.org/10.35159/kjss.2018.06.27.3.973

[40] Lee, C. J., Kim, J. W., \& Shin, D. S. (2015). Effects of soccer exercise after school on healthrelated physical fitness and cortisol in middle school boys. Korean Journal of Sports Science, 24(2), 1137-1144. UCI: G704-001369.2015.24.2.046

[41] Kim, S. H. (2001). The effect of body composition, blood lipids, leptin and anabolic hormone on aerobic exercise and resistance exercise in obesity girl students. (Unpublished Doctoral Dissertation). Chonnam National University, Kwangju, Korea.

[42] Cho, G. T. (2013). The influence of the elastic band exercise upon physical fitness, hand dexterity, cortisol level, and immune functions of men with intellectual disabilities. (Unpublished Doctoral Dissertation). Keimyung University, Daegu, Korea. 
[43] Kwon, Y. W., Kim, J. H., Kim, J. H., Kwon, K. S., \& Kim, H. C. (2004). Effects of 12 weeks training program on menstrual cycle in ovarian and growth-related hormone and cortisol. Korean Journal of Sport Science, 15(4), 8-18. UCI: G704-000739.2004.15.4.007

[44] Tremblay, M. S., Copeland, J. L., Van Helder, W. V. (2004). Effect of training status and exercise mode on endogenous steroid hormones in men. Journal of Applied Physiology, 96(2), 531-539. https://doi.org/10.1152/japplphysiol.00656.2003

[45] Min, B. I. (2012). The effects of running exercise on basic fitness, neurotransmitter and stress hormone in youth with mental retardation. Journal of Exercise Rehabilitation, 8(3), 149-159. UCI: G704-SER000008925.2012.8.3.013

[46] Paccotti, P., Minetto, M., Terzolo, M., Ventura, M., Ganzit, G. P., Borrione, P., Termine, A., \& Angeli, A. (2005). Effects of high-intensity isokinetic exercise on salivary cortisol in athletes with different training schedules: Relationships to serum cortisol and lactate. International Journal of Sports Medicine, 26(9), 747-755. https://doi.org/10.1055/s-2004-830449

\section{Authors}

Kun-Woo Park, Major in Special Physical Education; Researcher, Dept. of Physical Education, Graduate School, Yong-In University, Yongin, 17092, South Korea. He has earned a doctorate from Yongin University in Korea. His area of interest is disabled physical education and special physical education, and he has a career as a researcher. E-mail: ku-woo@hanmail.net

Seung-Yong Kim, Major in Sport Pedagogy, Professor, Major in PE, Graduate School of Education, Kyonggi University, Suwon, 16227, South Korea.

$\mathrm{He}$ is a professor of major in physical education at the Graduate School of Education at Kyonggi University in Korea. His areas of interest are teaching-learning factors, and he is researching teacher training and sports pedagogy. E-mail: dragonkim@kyonggi. $\underline{\text { ac. } \mathrm{kr}}$

Article submitted 2020-09-21. Resubmitted 2020-10-27. Final acceptance 2020-10-28. Final version published as submitted by the authors. 